\title{
Outcome after treatment of distal radius fractures in the elderly using the IlluminOss ${ }^{\circledast}$ System
}

\author{
Guido W. Van Oijen ${ }^{1} \cdot$ Paul A. Vegt $^{2} \cdot$ Tjebbe Hagenaars $^{1} \cdot$ Esther M. M. Van Lieshout $^{1} \cdot$ Michael H. J. Verhofstad $^{1}$
}

Received: 16 August 2019 / Accepted: 17 December 2019 / Published online: 16 January 2020

(c) The Author(s) 2020

\begin{abstract}
Purpose Distal radius fractures are very common and account for approximately $17 \%$ of all fractures treated. Multiple treatment methods are available to treat these fractures, both operative and nonoperative. This study aimed at evaluating the functional and clinical outcomes after treatment of distal radius fractures with the IlluminOss ${ }^{\circledR}$ System in adult patients.

Methods A retrospective case series was performed in a single-level two-trauma center. All consecutive adult patients with a distal radius fracture, treated with the IlluminOss ${ }^{\circledR}$ System between 01 August 2012 and 15 August 2015, were included in this study. Baseline patient characteristics and clinical data were retrospectively extracted from the medical records. Radial inclination, volar/dorsal tilt, ulnar variance, and radial length were measured on the latest available standard radiographs. In addition, patients were prospectively subjected to physical examination and were asked to complete the Disabilities of the Arm, Shoulder, and Hand, Patient-Rated Wrist Evaluation, and Short Form-36 questionnaires.

Results Twenty-six patients with 31 distal radius fractures were included. The median age at time of trauma was 77 years and $96 \%$ were females. Five patients developed a total of seven complications. Due to persisting pain one reoperation was performed, removing a small prominent part of the implant. Both patient-reported outcome scores and radiographic results were good to excellent.

Conclusions The IlluminOss ${ }^{\circledR}$ System is a feasible option to treat distal radius fractures with seemingly good clinical and functional outcome. One out of seven complications required surgical intervention. These outcomes justify more detailed prospective research.
\end{abstract}

Keywords Distal radius fracture $\cdot$ Elderly $\cdot$ IlluminOss $\cdot$ Intramedullary $\cdot$ Minimally invasive $\cdot$ Retrospective

\section{Introduction}

Fractures of the distal radius account for an estimated $17 \%$ of all fractures treated in US Emergency Departments and make up one of the most common osteoporotic fractures [1, 2]. Because of the osteoporotic character of distal radius fractures, elderly women are most likely to sustain a distal radius fracture with a female:male ratio of about $3: 1$ and a peak incidence between 60 and 69 years of age [3-5]. The absolute number of hospitalizations due to these fractures

Esther M. M. Van Lieshout

e.vanlieshout@erasmusmc.nl

1 Trauma Research Unit Department of Surgery, Erasmus MC, University Medical Center Rotterdam, P.O. Box 2040, 3000 CA Rotterdam, The Netherlands

2 Department of Surgery, Albert Schweitzer Hospital, Dordrecht, The Netherlands in The Netherlands in patients aged 50 years and older increased from 877 in 1997 to 2912 in 2009 and a further increase is expected $[3,4]$. This will bring a concomitant increase in demand for health care resources $[6,7]$.

Fractures of the distal radius can be treated operatively or non-operatively. Operative treatment can be done by external fixation or internal fixation using pins, screws, plates, or intramedullary nails. The IlluminOss ${ }^{\circledR}$ System (IlluminOss ${ }^{\circledR}$ Medical, East Providence, RI, USA) is a minimally invasive, patient-conforming, intraosseous fracture stabilization system [8]. A small incision of approximately $1.5-2 \mathrm{~cm}$ is required to insert an inflatable balloon into the medullary canal. The balloon, which spans the fracture, is infused with a monomer that polymerizes and hardens by applying blue light. This results in a stable and patient-conformed implant that can provide longitudinal strength and rotational stability (Fig. 1). The minimally invasive nature of the procedure and immediate start of functional after-treatment without plaster 

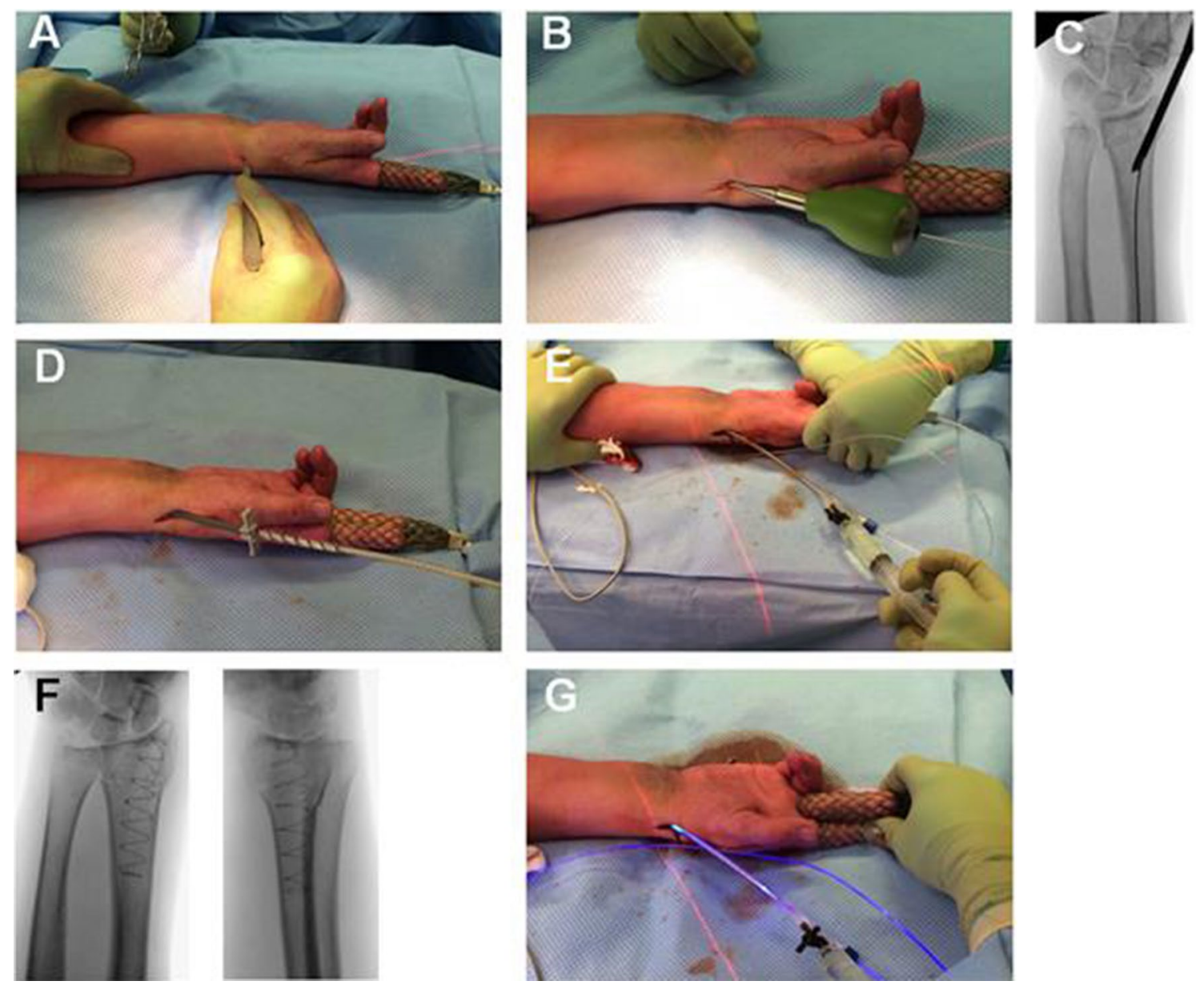

Fig. 1 Using the IlluminOss ${ }^{\circledR}$ System for fixating a distal radius fracture. a $1.5-2.0 \mathrm{~cm}$ incision over the radial styloid process, between the first and second extensor compartment to reach the periosteum. The branches of the superficial radial nerve are protected. b Access to the metaphyseal bone and medullary canal and insertion of a $1.5 \mathrm{~mm}$ guide-wire. c Correct position is verified by intra-operative fluoroscopy. d Flexible balloon catheter is placed intramedullary over the guide-wire spanning the fracture. e Infusion of liquid monomeric material and expansion of the balloon conforming to the patient's unique medullary canal. f Verification of adequate fracture reduction, correct balloon position, and balloon expansion. g Polymerization (hardening) of the infused monomer by applying visible $(436 \mathrm{~nm})$ light, creating a patient-conforming intramedullary implant cast immobilization are considered the main strengths of this device [8].

We expect that treating patients with the IlluminOss ${ }^{\circledR}$ System will result in excellent recovery of function; however, there are no literature data to confirm this. Therefore, the aim of this study was to evaluate functional and clinical outcomes after treatment of distal radius fractures with the IlluminOss ${ }^{\circledR}$ System in adult patients.

\section{Materials and methods}

\section{Patients and setting}

All adult patients with a distal radius fracture, treated with the IlluminOss ${ }^{\circledR}$ System between 01 August 2012 and 15
August 2015 at a level II trauma center, were included in this retrospective study. Patients with both extra- and intraarticular fractures were eligible. Patient selection for IlluminOss ${ }^{\circledR}$ treatment was done by the treating surgeon (PAV). The main selection criteria were the need and ability for fast return to daily activities and fracture type. Patients with a pathological or open fracture (i.e., Gustilo type II or III) were excluded. The local Medical Research Ethics Committee has given a waiver for this study. All patients participating in the follow-up measurement provided informed consent.

\section{Data collection and outcomes assessment}

The medical files of all patients were reviewed and the following patient-related parameters were retrieved: age, gender, comorbidities, ASA-classification, trauma 
mechanism, and additional injuries. The interventionrelated variables recorded were: time between injury and surgery, length and diameter of polyethylene terephthalate (PET) balloon used, peroperative complications (i.e., reduction problems, technical device-related problems, or iatrogenic damage), duration of surgery (i.e., total time of operation room use and net time for surgery). Finally, hospital length of stay, discharge destination, and physical therapy details were collected from the medical files.

Radiographic evaluation was done in duplicate (GWVO and $\mathrm{TH}$ ). Fractures were classified according to the $\mathrm{AO} /$ OTA-classification [9]. Radial inclination, volar/dorsal tilt, ulnar variance, and radial length were measured digitally in the Picture Archiving and Communication System (PACS) on the latest available standard posteroanterior and lateral wrist radiographs. Fracture consolidation and the Lidstrom score were also determined from these radiographs [10]. Measurements were averaged. Discrepancies were resolved by consensus.

The primary outcome measure was infection rate. Infectious complications were divided into superficial (i.e., minor or treated with oral antibiotics only) and deep (i.e., major or requiring surgical intervention, readmission, or intravenous antibiotics) by applying the criteria of the Centers for Disease Control and Prevention [11].

Patients were invited to visit the outpatient department. A trained researcher (GWVO) measured range of motion (ROM) with a goniometer, and grip strength with a Jamar ${ }^{\circledR}$ Hydraulic Hand Dynamometer. Measurements were standardized. Patients were also asked to complete the following questionnaires: disabilities of the arm, shoulder, and hand (DASH), patient-rated wrist evaluation (PRWE), and the level of pain during specified activities (Numeric rating scale, NRS), health-related quality of life (Short-form-36, SF-36). An additional questionnaire asked about the time to regaining independence in activities of daily living (ADL) and the use of physical therapy.

\section{Data analysis}

Descriptive analysis was performed using the Statistical Package for the Social Sciences (SPSS) version 21.0 (SPSS, Chicago, Ill., USA). Data are reported following the STROBE guidelines [12]. Continuous data all deviated from the Normal distribution and are, therefore, shown as median with quartiles. Categorical data are shown as number with percentage. Spearman's rank correlation tests were performed in order to determine the correlation of the Lidstrom score with the DASH, PRWE, flexion-extension arch, deviation arch, and pronation-supination arch.

\section{Results}

\section{Patient and intervention characteristics}

Approximately 1500 patients ( $>60$ years old) were treated for a wrist fracture (ICD-10 code S52.5) between 01 August 2012 and 15 August 2015 in this level II trauma center. In about a quarter of these patients this concerned an extraarticular distal radius fracture. Only one of the four trauma surgeons in this trauma center treated patients with the IlluminOss ${ }^{\circledR}$ System and offered this as an experimental treatment option. This resulted in a total of 26 patients with 31 distal radius fractures that were treated with the IlluminOss ${ }^{\circledR}$ System. Eighteen patients with 21 fractures underwent physical examination and completed the questionnaires at a median of $21\left(P_{25}-P_{75} 18-36\right)$ months after fracture. Four patients had deceased and four others wished not to participate. Table 1 shows the patient characteristics of the entire study population. The median age at time of trauma was 77 years and the majority of patients $(N=25$; $96 \%)$ females. Most patients $(N=22 ; 85 \%)$ had an ASAscore I or II. A fall from standing height was the cause of the injury in $25(96 \%)$ patients.

The intervention characteristics are outlined in Table 2. In 29 fractures, a single incision at the radial styloid of $1.5 \mathrm{~cm}$

Table 1 Patient characteristics

\begin{tabular}{|c|c|c|c|}
\hline & $\begin{array}{l}\text { All patients, } \\
N=26\end{array}$ & $\begin{array}{l}\text { Unilateral } \\
\text { fractures, } \\
N=20^{\mathrm{a}}\end{array}$ & $\begin{array}{l}\text { Bilateral } \\
\text { fractures, } \\
N=10\end{array}$ \\
\hline Age (years) & $77(70-85)$ & & \\
\hline Female gender & $25(96 \%)$ & & \\
\hline \multicolumn{4}{|c|}{ ASA-classification } \\
\hline 1 & $6(23 \%)$ & & \\
\hline 2 & $16(62 \%)$ & & \\
\hline 3 & $4(15 \%)$ & & \\
\hline 4 & $0(0 \%)$ & & \\
\hline \multicolumn{4}{|c|}{ AO-classification $^{a}$} \\
\hline 23-A2 & $12(40 \%)$ & $5(25 \%)$ & $7(70 \%)$ \\
\hline 23-A3 & $14(47 \%)$ & $11(55 \%)$ & $3(30 \%)$ \\
\hline $23-\mathrm{C} 2$ & $3(10 \%)$ & $3(15 \%)$ & \\
\hline $23-\mathrm{C} 3$ & $1(3 \%)$ & $1(5 \%)$ & \\
\hline $\begin{array}{c}\text { Right-side } \\
\text { affected }\end{array}$ & $17(55 \%)$ & & \\
\hline \multicolumn{4}{|c|}{ Trauma mechanism } \\
\hline Simple fall & $25(96 \%)$ & & \\
\hline Bike crash & $1(4 \%)$ & & \\
\hline $\begin{array}{l}\text { Concomitant } \\
\text { injuries }\end{array}$ & 1 & & \\
\hline
\end{tabular}

Data are shown as median $\left(P_{25}-P_{75}\right)$ or as $N(\%)$

${ }^{\text {a }}$ Radiographs of one patient were not retrieved 
Table 2 Intervention characteristics

\begin{tabular}{|c|c|c|c|c|}
\hline & \multicolumn{2}{|c|}{ All patients, $N=26$} & \multicolumn{2}{|c|}{ All fractures, $N=31$} \\
\hline & $N$ & & $N$ & \\
\hline Days between ER presentation and surgery & 26 & $9(6-12)$ & & \\
\hline Surgical time excl. anesthesia (min) & 26 & $50(41-87)$ & & \\
\hline Unilateral & 21 & $47(37-61)$ & & \\
\hline Bilateral & 5 & $87(58-93)$ & & \\
\hline Balloon length & & & 31 & \\
\hline $160 \mathrm{~mm}$ & & & & $27(87 \%)$ \\
\hline $180 \mathrm{~mm}$ & & & & $4(13 \%)$ \\
\hline Balloon diameter & & & 31 & \\
\hline $11 \mathrm{~mm}$ & & & & $30(97 \%)$ \\
\hline $9 \mathrm{~mm}$ & & & & $1(3 \%)$ \\
\hline Peroperative complication & & & 31 & \\
\hline Reduction difficulty requiring extra incision & & & & $2(7 \%)$ \\
\hline Admission time (days) & 26 & $1(1-2)$ & & \\
\hline Discharge destination & 26 & & & \\
\hline Home & & $23(92 \%)$ & & \\
\hline Nursing home & & $1(4 \%)$ & & \\
\hline Rehabilitation center & & $1(4 \%)$ & & \\
\hline Unknown & & $1(4 \%)$ & & \\
\hline
\end{tabular}

Data are shown as median $\left(P_{25}-P_{75}\right)$ or as $N(\%)$
Table 3 Complications

\begin{tabular}{lll}
\hline & \multicolumn{2}{l}{ All fractures, $N=31$} \\
\cline { 2 - 3 } & $N$ & \\
\hline Complications & 31 & $7(22 \%)$ \\
Superficial surgical site infection & & $2(6 \%)$ \\
Neurapraxia radial superficial nerve & $2(6 \%)$ \\
CRPS & $1(3 \%)$ \\
Persisting ulnar pain & $1(3 \%)$ \\
Implant-related pain & $1(3 \%)$ \\
\hline
\end{tabular}

Data are shown as $N(\%)$

was made for the introduction of the IlluminOss ${ }^{\circledR}$ balloon. In two cases (7\%) an extra (dorsal) incision was needed to acquire an adequate fracture reduction. The median surgical time, excluding anesthesia was $47 \mathrm{~min}$ for unilateral fractures and $87 \mathrm{~min}$ for bilateral fractures. After a median admission time of 1 day, 23 (92\%) patients were discharged to their home.

\section{Complications}

Five patients developed a total of seven complications after surgery (Table 3). Two superficial infections were treated successfully with antibiotics. Two patients had neurapraxia of the superficial radial nerve, which was self-limiting. One patient reported persisting ulnar pain at 9 months after surgery requiring oral pain medication. One patient had pain around the radial styloid, which is the entrance point of the implant. At both physical and radiographic examination the implant appeared proud, irritating soft tissues (Fig. 2). Removing this part of the implant resulted in a complete relief of complaints.

\section{Radiographic results}

Out of the 31 fractures, 30 fractures had at least one postoperative radiograph. Twenty patients had radiographic evaluation beyond 6 weeks after surgery. The median time to last $\mathrm{X}$-ray was 177 days after surgery. Twenty-three fractures (77\%) showed good or excellent fracture reduction according to the Lidstrom criteria (Table 4). Twenty-three (77\%) fractures showed a dorsal angulation with a median of 3 $\left(P_{25}-P_{75} 1-8\right)$ of the fracture fragment at the last available radiograph. This was the most common deformity that was responsible for lower Lidstrom scores. No signs of late secondary loss of reduction were seen.

The other seven fractures showed a volar angulation with a median of $5\left(P_{25}-P_{75} 1-8\right)$. All patients with radiographs beyond 6 weeks after surgery $(N=20)$, with a median time to last X-ray of 177 days after surgery, showed radiographic healing. Apart from increased sclerosis around the implant, no other bone abnormalities (i.e. degeneration or lysis) were seen. Although the exact borders of the implant are not clearly visible on conventional X-rays, during follow-up we saw no lucent zones (indicating loosening) within the bone marrow. 


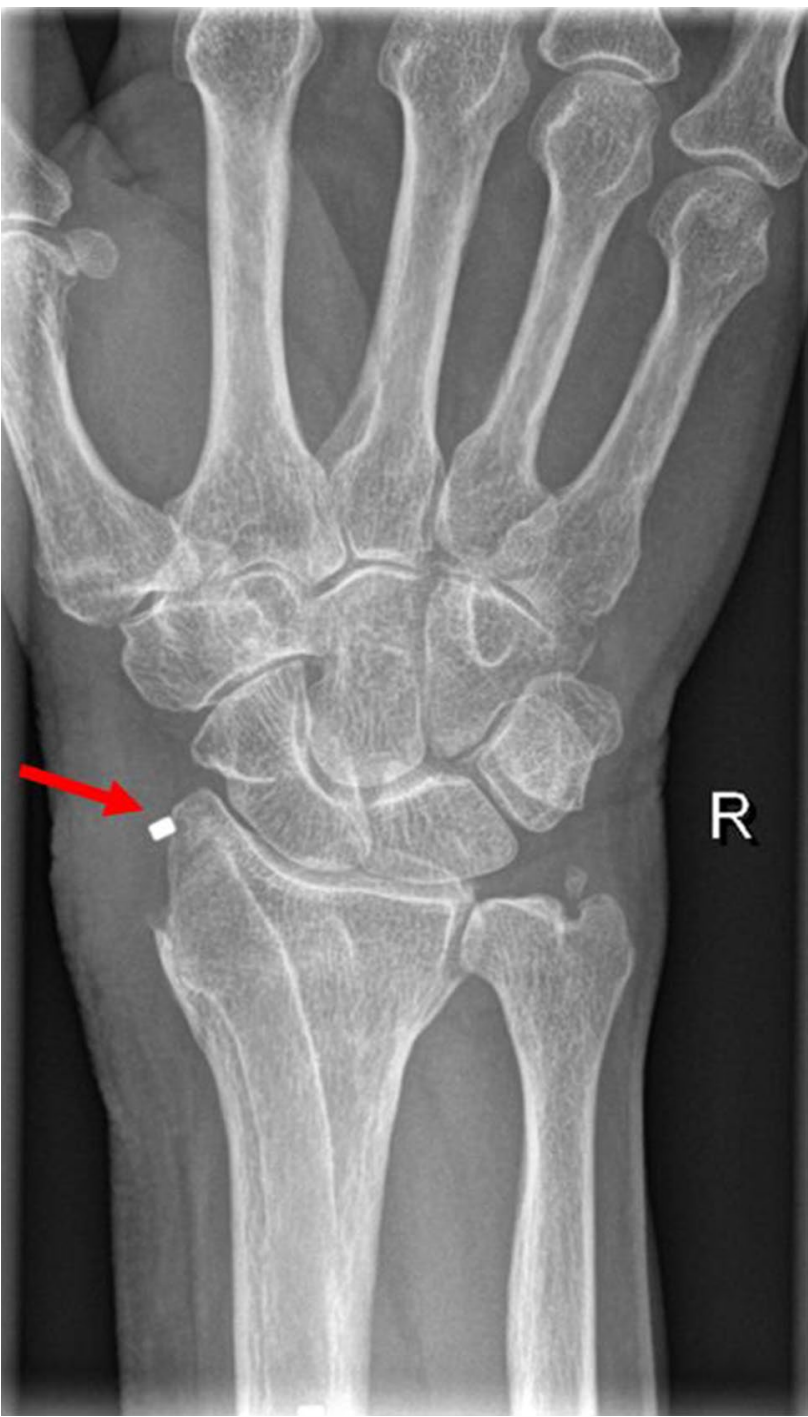

Fig. 2 PA-radiograph at one year and 4 months after primary surgery. A small part of the implant is sticking out just proximal of the radial styloid, access point to the intramedullary canal during primary operation

Table 4 Radiographic results

\begin{tabular}{ll}
\hline & All fractures, $N=30^{\mathrm{a}}$ \\
\hline Radial inclination $\left(^{\circ}\right)$ & $23.5(17-27)$ \\
Ulnar variance $(\mathrm{mm})$ & $3(1-5)$ \\
Volar angulation $\left(^{\circ}\right)(7$ fractures $)$ & $5(1-8)$ \\
Dorsal angulation $\left(^{\circ}\right)(23$ fractures $)$ & $3(1-8)$ \\
Lidström classification & \\
Excellent & $6(20 \%)$ \\
Good & $17(57 \%)$ \\
Fair & $5(17 \%)$ \\
Poor & $2(7 \%)$ \\
\hline
\end{tabular}

Data are shown as median $\left(P_{25}-P_{75}\right)$ or as $N(\%)$

${ }^{a}$ Radiographs of one patient were not retrieved
Table 5 Functional outcome: patient-rated outcome measures

\begin{tabular}{ll}
\hline & All patients, $N=18$ \\
\hline DASH score & $9(1-26)$ \\
PRWE total score & $9(0-25)$ \\
PRWE pain score & $1(0-17)$ \\
PRWE functional score & $5(0-17)$ \\
Pain at rest $^{\mathrm{a}}$ & $0(0-0)$ \\
Pain at work $^{\mathrm{a}}$ & $0(0-2)$ \\
Pain during housekeeping activities $^{\mathrm{a}}$ & $0(0-2)$ \\
SF-36 total score & $102(92-111)$ \\
SF-36 physical component score & $46(33-54)$ \\
SF-36 mental component score & $60(54-63)$ \\
\hline
\end{tabular}

Data are shown as median $\left(P_{25}-P_{75}\right)$

${ }^{\text {a } O n l y ~ p a t i e n t s ~ w h o ~ c o m p l e t e d ~ t h e ~ s e t ~ o f ~ q u e s t i o n n a i r e s ~}$

Table 6 Functional outcome: clinical measures

\begin{tabular}{lc}
\hline & All fractures, $N=23$ \\
\hline Loss of ROM (degrees) & \\
Flexion-extension & $5(-6-26)=8 \%$ \\
Ulnar deviation-radial deviation & $8(1-24)=18 \%$ \\
Pronation-supination & $1(-7-22)=0.1 \%$ \\
Loss of grip strength $(\mathrm{kg})$ & $2(0-7)=20 \%$ \\
\hline
\end{tabular}

${ }^{\mathrm{a} O n l y}$ patients who underwent physical examination

\section{Functional outcome}

Table 5 shows the results of the questionnaires. Both the DASH score and the PRWE total score had a median of nine points. The median pain score during specified activities was zero.

Patients with a unilateral fracture showed $18 \%$ loss of range of deviation and a $20 \%$ loss in grip strength in the affected side as compared to the uninjured wrist (Table 6). Both the flexion-extension and pronation-supination restriction were less than $10 \%$. This was in line with statements of the treating surgeon that patients achieved full range of motion. A statistically significant correlation was found between the Lidstrom score and flexion-extension arc with a Spearman's rho of $-0.437(p=0.047)$. Correlations of the Lidstrom score with other functional outcomes (i.e., DASH score, PRWE score, deviation arc, and pro-supination arc) did not reach statistical significance (Spearman's rho from 0.2387 to 0.313 ).

\section{Discussion}

The aim of this study was to evaluate outcome of treatment of distal radius fractures with a new patient-conforming device, the IlluminOss ${ }^{\circledR}$ system. The essence of the system 
is that after percutaneous introduction a final indirect fracture reduction can be performed and subsequently the monomer is hardened to provide stability. Clinical and functional outcome in terms of ROM, DASH and PRWE scores at 21-month follow-up were good, as was radiological outcome. Seven complications developed in 31 fractures, of which one required a small surgical intervention.

The retrospective design could be considered a limitation of the current study. With only 31 fractures included and a considerable rate of missing data for specific outcomes, the sample size was relatively small. Increasing the population was not feasible due to start of a prospective study [13]. The non-randomized design may also be considered a limitation. However, given the large number of publications on outcome after treatment of distal radius fractures, we preferred to compare the results with published data. Follow-up visits and medical record notes were not standardized. The course of improvement of function, ADL independence, and the amount of physical therapy provided were not reliably documented and, therefore, not analyzed. Moreover, as any retrospective study selection bias likely occurred since the decision to use the IlluminOss ${ }^{\circledR}$ system depended on the preference of the attending surgeon as well as logistical considerations. This may explain why the study population was relatively older and more often female patients than expected from recent literature [14-16].

The DASH score (9 points) and PRWE score (9 points) seem slightly lower than published for other fixation methods. Currently, no patient-reported outcome scores are available for treatment of distal radius fractures with the IlluminOss ${ }^{\circledR}$ System. A previous study of Costa et al. reported a mean DASH of 13.0 at 1 year after volar plate fixation and 16.2 after percutaneous fixation with K-wires [17]. Mean PRWE scores were 13.9 after volar plate fixation and 15.3 after percutaneous fixation with K-wires [17]. This may suggest that the patients in the current study experienced less disability and a better function. An explanation for this could be the fact that the IlluminOss ${ }^{\circledR}$ system is a percutaneous, patient-conforming fracture stabilization system. However, a longer follow-up duration in the current study (21 months) may also influence the difference in scores. Previous studies suggest that further improvement of functional scores can be expected after 1 year [18]. Due to the retrospective and non-comparative design, no conclusions can be drawn with regard to the course of functional improvement. The strong feeling is that patients treated with the IlluminOss ${ }^{\circledR}$ system experience a faster functional recovery than those with non-operative treatment or open reduction and plate fixation. Therefore, a prospective study was started [13].

In this study we found a complication rate of $22 \%$, where in one case a re-operation was performed, approximately 2 years after primary surgery. Literature provides a large diversity of complications and complication rates for K-wire fixation
(6.5-28\%), plate fixation (3.2-36\%), and intramedullary nailing (18-36\%) [17, 19-26]. In this study the percentage of complications was within these ranges. Since every fixation method has its own specific complications, these percentages cannot easily be compared.

Good or excellent radiographic results after surgical treatment of distal radius fractures have been reported frequently [22, 25, 27-29]. Brennan et al. found superior radiological outcome in favor of volar plate fixation, when comparing it to percutaneous K-wire fixation [28]. The radial inclination was 22.1 and 21.3 , the ulnar variance was -0.5 and 0.1 , and the volar tilt was 4.2 and 1.7. These values correspond well with previously published studies [22, 29]. The current study showed similar values except for the volar tilt, where the majority of the fractures showed a dorsal tilt at final followup. From the available radiographs, it was not possible to judge if this was due to primary reduction errors or to secondary collapse, because for most patients no radiographs within the first week after surgery were available.

During follow-up of our study subjects, no removal of implants was necessary. If necessary (e.g. due to deep infection, loss of reduction or re-fracture), the implant can be removed in three ways: (1) by simple grabbing and pulling. Especially if a loosened implant is the likely cause of secondary dislocation, it will be easy, (2) after pre-drilling a hole in the balloon, a Steinmann's pin, threaded guidewire, or screw can be inserted to extract the implant, with or without the use of the IlluminOss ${ }^{\circledR}$ removal slap hammer, (3) an ultrasonic $63 \mathrm{kHz}$ implant-pulverizing device is available (IlluminOss ${ }^{\circledR}$ Medical, East Providence, RI, USA). This device pulverizes the cured polymer, but leaves the balloon intact. After that, the emptied balloon can be easily extracted.

In conclusion, this study showed good functional and radiographic outcomes, with similar complication rates as in recent literature. A larger and prospective study is needed in order to confirm this and to provide insight into the timing of functional recovery.

Funding No external funding was received for this study.

\section{Compliance with ethical standards}

Conflict of interest Author GWVO, author PAV and author TH declare that they have no conflict of interest. Author EMMVL and author MHJV received a research grant from IlluminOss Medical BV for an investigator initiated prospective study. EMMvL is also the scientific coordinator Research Program of the Osteosynthesis and Trauma Care Foundation.

Open Access This article is licensed under a Creative Commons Attribution 4.0 International License, which permits use, sharing, adaptation, distribution and reproduction in any medium or format, as long as you give appropriate credit to the original author(s) and the source, provide a link to the Creative Commons licence, and indicate if changes were made. The images or other third party material in this article are 
included in the article's Creative Commons licence, unless indicated otherwise in a credit line to the material. If material is not included in the article's Creative Commons licence and your intended use is not permitted by statutory regulation or exceeds the permitted use, you will need to obtain permission directly from the copyright holder. To view a copy of this licence, visit http://creativecommons.org/licenses/by/4.0/.

\section{References}

1. Chung KC, Spilson SV. The frequency and epidemiology of hand and forearm fractures in the United States. J Hand Surg Am. 2001;26(5):908-15.

2. Brogren E, Petranek M, Atroshi I. Incidence and characteristics of distal radius fractures in a southern Swedish region. BMC Musculoskelet Disord. 2007;8:48.

3. de Putter CE, Selles RW, Polinder S, Hartholt KA, Looman CW, Panneman MJ, et al. Epidemiology and health-care utilisation of wrist fractures in older adults in The Netherlands, 1997-2009. Injury. 2013;44(4):421-6.

4. Polinder S, Iordens GI, Panneman MJ, Eygendaal D, Patka P, Den Hartog D, et al. Trends in incidence and costs of injuries to the shoulder, arm and wrist in The Netherlands between 1986 and 2008. BMC Public Health. 2013;13:531.

5. Cummings SR, Kelsey JL, Nevitt MC, O’Dowd KJ. Epidemiology of osteoporosis and osteoporotic fractures. Epidemiol Rev. 1985; 7:178-208.

6. Morin SN, Lix LM, Majumdar SR, Leslie WD. Temporal trends in the incidence of osteoporotic fractures. Curr Osteoporos Rep. 2013;11(4):263-9.

7. Shauver MJ, Yin H, Banerjee M, Chung KC. Current and future national costs to medicare for the treatment of distal radius fracture in the elderly. J Hand Surg Am. 2011;36(8):1282-7.

8. Vegt P, Muir JM, Block JE. The photodynamic bone stabilization system: a minimally invasive, percutaneous intramedullary polymeric osteosynthesis for simple and complex long bone fractures. Med Dev (Auckl). 2014;7:453-61.

9. Marsh JL, Slongo TF, Agel J, Broderick JS, Creevey W, DeCoster TA, et al. Fracture and dislocation classification compendium-2007: Orthopaedic Trauma Association classification, database and outcomes committee. J Orthop Trauma. 2007;21(10 Suppl):S1-133.

10. Lidstrom A. Fractures of the distal end of the radius: a clinical and statistical study of end results. Acta Orthop Scand Suppl. 1959;41:1-118.

11. Berrios-Torres SI. Evidence-based update to the US Centers for Disease Control and Prevention and Healthcare Infection Control Practices Advisory Committee Guideline for the Prevention of Surgical Site Infection: Developmental Process. Surg Infect (Larchmt). 2016;17(2):256-61. https://doi.org/10.1089/ sur.2015.264.

12. von Elm E, Altman DG, Egger M, Pocock SJ, Gotzsche PC, Vandenbroucke JP, et al. Strengthening the reporting of observational studies in epidemiology (STROBE) statement: guidelines for reporting observational studies. BMJ. 2007;335(7624):806-8. https://doi.org/10.1136/bmj.39335.541782.AD.

13. Hagenaars T, Van Oijen GW, Roerdink WH, Vegt PA, Vroemen JP, Verhofstad MH, et al. Functional recovery after treatment of extra-articular distal radius fractures in the elderly using the IlluminOss(R) System (IO-Wrist); a multicenter prospective observational study. BMC Musculoskelet Disord. 2016;17:235. https://doi.org/10.1186/s12891-016-1077-9.

14. Diamantopoulos AP, Rohde G, Johnsrud I, Skoie IM, Hochberg M, Haugeberg G. The epidemiology of low- and high-energy distal radius fracture in middle-aged and elderly men and women in Southern Norway. PLoS ONE. 2012;7(8):e43367. https://doi. org/10.1371/journal.pone.0043367.

15. Wilcke MK, Hammarberg H, Adolphson PY. Epidemiology and changed surgical treatment methods for fractures of the distal radius: a registry analysis of 42,583 patients in Stockholm County, Sweden, 2004-2010. Acta Orthop. 2013;84(3):292-6. https://doi. org/10.3109/17453674.2013.792035.

16. Nellans KW, Kowalski E, Chung KC. The epidemiology of distal radius fractures. Hand Clin. 2012;28(2):113-25. https://doi. org/10.1016/j.hcl.2012.02.001.

17. Costa ML, Achten J, Parsons NR, Rangan A, Griffin D, Tubeuf $S$, et al. Percutaneous fixation with Kirschner wires versus volar locking plate fixation in adults with dorsally displaced fracture of distal radius: randomised controlled trial. BMJ. 2014;349:g4807.

18. Brogren E, Hofer M, Petranek M, Dahlin LB, Atroshi I. Fractures of the distal radius in women aged 50 to 75 years: natural course of patient-reported outcome, wrist motion and grip strength between 1 year and 2-4 years after fracture. J Hand Surg Eur. 2011;36(7):568-76. https://doi.org/10.1177/1753193411409317.

19. McFadyen I, Field J, McCann P, Ward J, Nicol S, Curwen C. Should unstable extra-articular distal radial fractures be treated with fixed-angle volar-locked plates or percutaneous Kirschner wires? A prospective randomised controlled trial. Injury. 2011;42(2):162-6. https://doi.org/10.1016/j.injury.2010.07.236.

20. Lee YS, Wei TY, Cheng YC, Hsu TL, Huang CR. A comparative study of Colles' fractures in patients between fifty and seventy years of age: percutaneous K-wiring versus volar locking plating. Int Orthop. 2012;36(4):789-94. https://doi.org/10.1007/s0026 4-011-1424-2.

21. Egol K, Walsh M, Tejwani N, McLaurin T, Wynn C, Paksima $\mathrm{N}$. Bridging external fixation and supplementary Kirschnerwire fixation versus volar locked plating for unstable fractures of the distal radius: a randomised, prospective trial. J Bone Jt Surg Br. 2008;90(9):1214-21. https://doi.org/10.1302/0301620X.90B9.20521.

22. Arora R, Lutz M, Deml C, Krappinger D, Haug L, Gabl M. A prospective randomized trial comparing nonoperative treatment with volar locking plate fixation for displaced and unstable distal radial fractures in patients sixty-five years of age and older. $\mathrm{J}$ Bone Jt Surg Am. 2011;93(23):2146-53. https://doi.org/10.2106/ JBJS.J.01597.

23. Williksen JH, Frihagen F, Hellund JC, Kvernmo HD, Husby T. Volar locking plates versus external fixation and adjuvant pin fixation in unstable distal radius fractures: a randomized, controlled study. J Hand Surg Am. 2013;38(8):1469-76. https://doi. org/10.1016/j.jhsa.2013.04.039.

24. Gradl G, Mielsch N, Wendt M, Falk S, Mittlmeier T, Gierer P, et al. Intramedullary nail versus volar plate fixation of extraarticular distal radius fractures: two year results of a prospective randomized trial. Injury. 2014;45(Suppl 1):S3-S8.

25. Dremstrup L, Skjaerbaek MS, Olesen S, Hogh A, Hansen TB. Good radiological and functional results after intramedullary nailing of distal radius fractures. J Plast Surg Hand Surg. 2013;47(4):286-8. https://doi.org/10.3109/2000656X.2012.76046 6.

26. Hardman J, Al-Hadithy N, Hester T, Anakwe R. Systematic review of outcomes following fixed angle intramedullary fixation of distal radius fractures. Int Orthop. 2015;39(12):2381-7. https ://doi.org/10.1007/s00264-015-2763-1.

27. Kumar S, Khan AN, Sonanis SV. Radiographic and functional evaluation of low profile dorsal versus volar plating for distal radius fractures. J Orthop. 2016;13(4):376-82. https://doi. org/10.1016/j.jor.2016.06.017.

28. Brennan SA, Kiernan C, Beecher S, O'Reilly RT, Devitt BM, Kearns SR, et al. Volar plate versus k-wire fixation of distal radius 
fractures. Injury. 2016;47(2):372-6. https://doi.org/10.1016/j.injur y.2015.08.040.

29. Karantana A, Downing ND, Forward DP, Hatton M, Taylor AM, Scammell BE, et al. Surgical treatment of distal radial fractures with a volar locking plate versus conventional percutaneous methods: a randomized controlled trial. J Bone Jt Surg Am. 2013;95(19):1737-44. https://doi.org/10.2106/JBJS.L.00232. 